\title{
GROWING UP: AN URBAN DESIGN APPROACH BASED ON INCREASED DENSITY
}

\author{
OLIVIER CHAMEL \& BERND DAHLGRUEN \\ School of Architecture and Engineering Technology, Hafen City University, Germany
}

\begin{abstract}
Throughout history cities have been the physical manifestation of human progress and a place of unique opportunities in terms of welfare, social mobility and economic prosperity. Under the pressure of continued global growth, cities have become complex multi-layered organisms and are facing an increasing number of challenges such as environmental quality, social balance, waste disposal, transportation systems, housing accessibility and urban space quality to name a few. In the context of economic and demographic pressure, one can wonder if large and dense urban centers can continue to grow while meeting complex functional needs and remaining attractive places to live. This paper proposes to discuss a strategy of urban development based on increasing the density of historical city centers by means of adding floors to existing buildings. In essence this concept is in keeping with the notion of urban growth as an incremental process where new building units and infrastructures are added and intertwined with existing ones. It also recognizes the value of old urban profiles. This urban design process has been developed and experimented in Hamburg, Germany for a number of years and presents an original and promising approach to urban growth. It has been relying on the use of lightweight construction, mainly wood based systems, due in part to their relative lightweight, ease of assembly and insulation value. This approach encompasses many fields of study as it deals with zoning laws, construction codes, structures, building systems, social identity and architectural expression. It constitutes an attempt to minimize gentrification, urban sprawl and create quality housing at attractive prices in desirable neighborhoods. A goal of this paper is to assess the impact of this urban design approach and to identify possible applications in other urban contexts.
\end{abstract}

Keywords: urban design, increased density, rooftop additions, sustainable urban growth, resilient cities.

\section{INTRODUCTION}

Today half of humanity's 7.6 billion people live in cities and it is projected that 5 billion people will live in urban areas by 2030 (United Nations Sustainable Development Report 2020). This trend of sustained urban growth is clearly driven by the many appeals of cities including opportunities of upward social and economic mobility [8]. According to the United Nations Sustainable Development Goals it is estimated that urban centers currently represent $70 \%$ of the world's gross domestic product. As cities continue to grow often into large or very large urban centers, they face increasingly complex challenges. In fact, the larger the city the more difficult it becomes to manage the flow of people, vehicles, water, waste and resources in general [9]. Even more so in a sustainable manner. Just as urban centers are undoubtedly places of great opportunities, they are also known to induce stress due to increased commute time, air quality and access to affordable healthcare and housing. Access to affordable housing within a reasonable distance of peoples' workplace is a particularly challenging issue. Typically, urban residents of large cities live in suburbs because the cost of housing downtown is disproportionately high compared to their income. As a result, they have substantial commute time to work generating both stress and a loss of productivity. The issue of affordable housing in urban centers is important in financial and practical terms but also in terms of access to services, culture, and social interactions. The idea of city centers being vibrant places composed of diverse ethnic and socio-economic groups represents a noble goal that is not always easily achievable. Mechanisms such as rent control and 
subsidized housing provide opportunities for low and middle-income individuals to live in urban settings and also close to their workplace. Unfortunately, these opportunities tend to be limited because of the limited housing supply as most of the production of new housing units occurs at the periphery of existing cities or in more distant suburbs, therefore posing the question of urban growth.

Metropolitan regions have been growing worldwide as rural areas continue to lose residents who are moving to cities. This trend has been well documented and mapped in Europe for many decades [1]. But the crucial question remains, how should cities grow? There are several different scenarios for urban growth. Cities can grow by expanding into surrounding areas, in which case they become very large. Most people associate urban growth with this geographical expansion but there are clear limits to this approach. As a city expands geographically its infrastructure and services must also grow with it. However existing infrastructures such as sewage systems and road networks can only expand so much until they have to be completely upgraded. This form of growth tends to generate incalculable costs for the public sector and therefore has spatial and economic limits.

Another strategy for growth can be described as a re-densification of the city. It assumes that the city would become more compact and people would live closer together. This idea of urban growth can be difficult for people to imagine and tend to be fraught with reservations or is not recognized as an effective relief for the housing market. Practically speaking, urban re-densification can follow several strategies. Land can be developed in a denser fashion such as in the case of backyard development, additions, demolition and new construction. Derelict industrial and commercial properties can be converted to housing units through adaptive reuse conversion and rezoning. Another possible option would consist in building new properties on top of existing ones. This last option, though surprising at first, offers a number of sustainable features. One of its most obvious benefit is the fact that it does not consume any existing vacant land and therefore does not "seal" the ground or add storm water issues associated with the increase of impervious surfaces.

\section{OBJECTIVES OF THE STUDY AND METHODOLOGY}

In the context of global population increase, the objective of this paper is to present an alternative strategy of urban growth for existing dense cities. As previously stated, there are clear limits to the physical expansion of urban centers; this invites us to consider a new approach to the overall issue. The idea of building residential rooftop additions on a large scale makes logical sense though it is fraught with a number of challenges in terms of technology, legal environment, sustainability and cost to name a few. Therefore, we propose to discuss both challenges and opportunities associated with this form or residential projects in order to develop a clear overview about the issue at stake. Our method of analysis will consist in evaluating positives and negatives as it relates to the socio-economic context, structure and technology, sustainability, legal issues and the overall economic feasibility. The data used in this paper was gathered in the context of a research project under the direction of Professor Bernd Dahlgruen in the city of Hamburg, Germany.

One of the benefits of building on top of existing structures is that it does not reduce the economic use of the existing urban fabric as is the case of adaptive reuse projects and preserves a mix of commercial and residential uses. In addition, it does not displace people living in the existing building due to demolition and new construction and does maintain the existing social fabric of a neighborhood. Other advantages lie in the fact that this strategy prolongs the economic and therefore the overall life of existing real estate by leaving it intact. This strategy also provides upgrades to existing structures especially in terms of energy efficiency. The only potential disadvantage is the disturbance to adjacent residents during the 
time of construction. However, this would appear to create only a minor impairment as these types of projects have a very short construction time.

However, as much as this form of housing development seems to be sustainable and socially acceptable, it is very important to identify and measure the impact and potential of these strategies in the broader context of long-term urban evolution in order to make a convincing case for it. In fact, local politicians and developers have expressed many concerns about these types of building additions as their feasibility was being evaluated [2]. Building professionals expressed well founded criticism regarding the design of these rooftop additions. It is in fact a construction challenge to add a new building component, which has to meet current requirements such as fire, sound and heat protection onto an existing building with completely different construction properties. What happens at the interface? How are the transitions constructed? What are the normative and legal requirements for the existing building, the new building and the transition? In consultation with construction experts, construction sample solutions were developed and made available to the public as part of the feasibility study for this type of project. There are obviously additional practical concerns regarding the construction site and its functionability. Often, there is simply not enough space for a construction site facility and it is not possible to set up a crane on a permanent basis. All these issues were taken into account in the development of a practical project planning. All project solutions included lightweight prefabricated components to be installed on the roof by means of a mobile crane in a couple of days at the most, preferably on a weekend. All other construction activities such as interior finishes and roofing would not require major site equipment.

Obviously, many of the concerns associated with this type of project are technical in nature and are associated with the ability of existing structures to carry additional loads. The compatibility between new requirements and old standards, especially with regards to fire and sound protection have also raised a number of questions. The tight physical constraints of constructing such projects can also appear to be challenging and generate excessive cost due to the unusual height of the construction site. In that case it may reduce the overall value of the existing building because of technical deficiencies. There are also legal concerns as existing buildings cannot be extended in accordance with current building legislation. Overall, city planners and politicians viewed rooftop building additions as having a very low impact on urban housing needs.

\section{SOCIO-ECONOMIC CONTEXT}

Over the past few decades, growing German cities such as Hamburg (see Fig. 1), Berlin or Munich have generated an increase in inner-city housing demand, due to the scarcity of land and few new housing projects. As a result, real estate prices have risen, and urban living has become more and more expensive for newcomers. As a consequence, the property prices for existing condominiums in the Hamburg metropolitan area in the 2011-2015 period have increased between $5 \%$ and $13 \%$ annually. Existing apartments in the Eimsbüttel area cost an average of $€ 2,500$ to $€ 3,000$ per square meter in 2011. In 2015 these apartments cost an average of $€ 3,000$ to $€ 4,000$ per square meter. In 2012 only $11 \%$ of the advertised rental apartments were for average income families and only $2 \%$ for low income families. The offering of affordable urban housing is far below the German average.

This sustained development in the real estate industry is leading to a gentrification process and threatens socially acceptable urban development. Therefore, we see urban densification by means of building additions as a form of development that can counteract this phenomenon because building additions can generate additional living space without using 


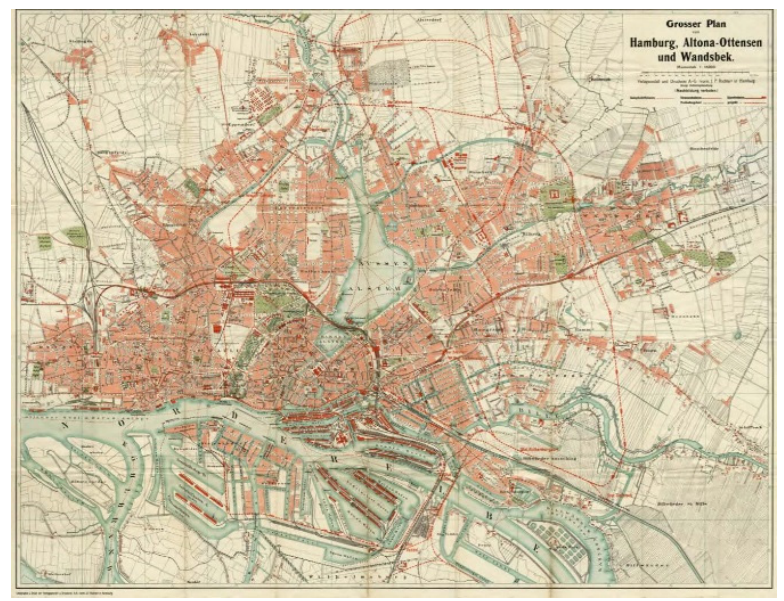

Figure 1: Map of the city of Hamburg in the 1900s.

additional land. These housing units do not necessarily have to become rental properties but rather subsidized apartments for low or middle-income families.

In addition, these building additions promote sustainable and ecological urban development since they emphasize inner-city living and compact infrastructure as opposed to urban sprawl.

\section{TECHNICAL AND STRUCTURAL CHALLENGES}

In Europe, most historical urban housing is built of stone and in Northern Europe mostly of brick. These materials have high compressive and load-bearing capacity, which can be easily determined by calculation. By measuring the room depth, floor heights and wall thickness of load-bearing walls, one can obtain all relevant parameters for an initial structural assessment. The most important criteria here are the direction of the ceilings span, the wall thicknesses, floor heights and the window proportion of the load-bearing walls. As a part of our feasibility study for this type of project, we have provided a calculation tool for initial structural assessments, which can be used to determine whether existing buildings have sufficient loadbearing capacity for rooftop building extensions in less than 30 minutes [4].

When researching historical building methods, we noticed that it is rarely the wall structures that are statically problematic, but rather the undersized foundations. Their loadbearing capacity cannot be determined in advance without planning documents. For this purpose, an area of the foundations would have to be exposed in order to determine the construction and its load-bearing capacity. This can also be done with the calculation tool we referred to earlier and which is available on the HCU website. However, if the foundations are undersized for a building extension, it is still possible to increase the load-bearing capacity of the soil and foundations by injecting cement-water emulsions. This method is inexpensive and can be carried out without major construction work in the existing structure and can be performed on the foundations of the exterior and interior walls.

In summary, it can be said that the load-bearing capacity of the existing structure is easy to determine, foundations can be strengthened with simple means if necessary, though loadbearing walls unfortunately cannot. In this respect, the absence of existing load-bearing walls is an obstacle for these types of additions. However, a few hours of work and simple calculations can determine the feasibility of a project at the beginning of the process. 
Though historical buildings in Hamburg are built with some type of masonry system and offer a good "base" for rooftop additions, the construction system most appropriate for such projects would have to be wood. When compared to concrete and masonry construction systems, timber construction systems have, in addition to the low dead loads further design advantages. Regardless of whether we consider a wooden frame, a panel, or box girder elements, these systems can be used with a high degree of precision. They can be prefabricated and assembled very quickly any time of the year as long as it is not raining (see Fig. 2). The prefabrication process implies quality control procedures and ensures a high manufacturing quality. The disadvantage of all wood systems lies in their vulnerability towards fire. For example wooden box girder elements are valuable when considered from a static point of view as they are light though cross-laminated timber panels have a much better dead-load to load-bearing capacity ratio.

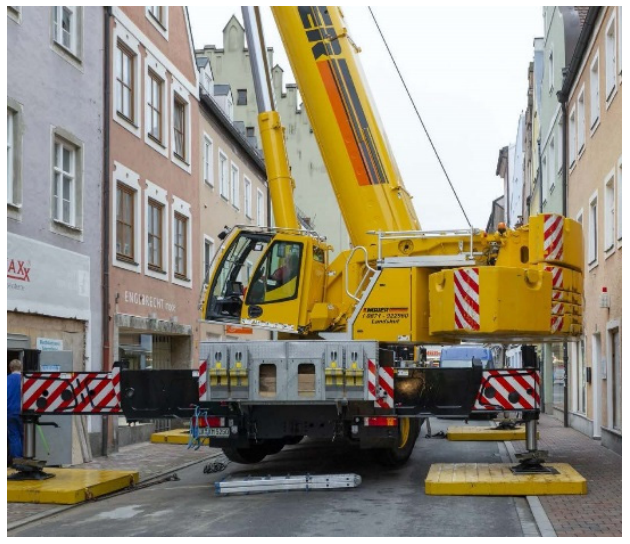

(a)

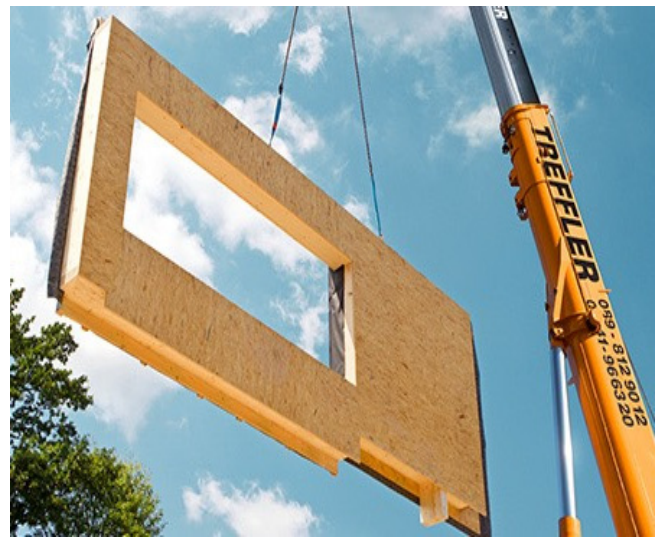

(b)

Figure 2: (a) Mobile crane; and (b) Prefabricated panel installation.

When designing lightweight structures, such as those used in rooftop additions, special attention must be paid to the issues of heat and moisture protection. Lightweight structures are often designed as frame structures and structural components are often located in the insulation cavity of a wall or roof system. Therefore, designers need to pay particular attention to issues such as thermal bridging, which constitutes a break in an insulated building envelope. Lightweight wood construction assemblies would then need to be designed as a multi-layered system in order to be air and vapor tight and provide adequate insulation. Lightweight construction has a low net weight and therefore little heat storage capacity, so the overall building envelope needs to be designed in such a way so that it provides adequate protection from the summer heat.

\section{SUSTAINABILITY AND ENERGY EFFICIENCY}

$40 \%$ of the total energy consumption in the European Union is associated with new building construction and operation of existing building stocks. The construction and real estate industry continue to grow across Europe therefore contributing to increased energy consumption and $\mathrm{CO}_{2}$ emissions. Given the ecological consequences associated with increased greenhouse gas emissions, the European Union adopted a mandatory directive on the overall energy efficiency of buildings. Member states of the European Union created 
national regulations aimed at reducing national energy consumption and $\mathrm{CO}_{2}$ emissions from buildings in order to meet agreed upon measurements and calculation specifications. Starting on September 31, 2020, only low-energy buildings would be approved by the EU. Lowenergy buildings are structures that have no or low energy requirements, mainly from renewable or locally generated sources. To achieve this 2020 target, member states of the EU are gradually introducing their national regulations on building energy consumption. The Federal Republic of Germany is also pursuing this strategy and implementing the EU directive currently with the Energy Saving Ordinance. Since building heating has the largest share of energy in the operation of residential buildings in Germany, efforts have been focused on the minimization of heat losses via the building envelope. These issues of insulation and heat gain are actually exacerbated by the fact that rooftop structures are especially exposed to the sun and cannot benefit from a night cooling cycle due to a lack of thermal inertia.

\section{LEGAL ENVIRONMENT}

Most building codes do not consider building additions and contain regulations that make this form of housing creation difficult or even impossible. For example, until 2015, Hamburg required elevators above a building height of $13 \mathrm{~m}$ and prohibited wood construction for fire safety reasons among other things. These regulations vary from country to country and should definitely be identified at the beginning of the project in order to be able to assess whether a building increase is feasible at all in the respective jurisdiction. As a part of the feasibility study for this project, we petitioned local politicians to adapt the jurisdiction for this type of re-densification. We only succeeded in this effort by making the following demonstration. The effectiveness of building extensions for creating living space was always considered too low due to the very small project sizes: "Rooftop additions are projects that typically create one or two residential units at a time!" Nevertheless, urban densification is a political goal of the state government in Hamburg and the exemptions granted by the authorities along with changes made to the building codes caught their interest and support.

With the help of our colleagues from the geoinformatics department, we determined the building-law potential for Hamburg on a building-by-building basis and arrived at a pure building-law housing potential of approximately 75,000 apartments [5], [6]. This number corresponds to the housing demand in Hamburg for 10 years. This determination does not take into account any construction and economic concerns, but only aspects of urban planning law, namely distance areas and maximum permissible building heights. We published this research online and shared it with a press release. The result was published in daily newspapers, discussed in the Bürgerschaft and finally exerted political pressure on the local government, which then partially overturned 140-year-old building regulations. Therefore, today in Hamburg we do not have any legal criteria in the building code that prevent rooftop additions. Demonstrating housing potential was and remains the most important step in getting interest and commitment at the political level for this form of urban re-densification.

\section{ECONOMIC FEASIBILITY}

However, the housing potential demonstrated above does not convince builders. They compare the construction prices with a traditional new building project, find out that the construction prices of building extensions are significantly higher and then state that building extensions are uneconomical. This approach is actually inaccurate because instead of focusing on construction costs only one needs to consider the overall project cost. In fact, in the case of rooftop additions, construction and planning costs are both more expensive. In addition, there are compensations for existing tenants and, if applicable, additional legal 
costs. Rooftop projects are also more expensive in terms of design and construction when compared to traditional projects. However, a key factor is that they do not consume additional land. Since the land costs actually exceed the additional costs, building extensions are very economical compared to traditional construction projects. Especially in the growing cities described above, the price of land relative to the overall project cost has exploded within the last ten years. In Hamburg, it has quadrupled within the last ten years and is as high as the construction costs. In the context of expensive cities rooftop additions can therefore turn into economically feasible projects.

\section{SUMMARY OF ANALYSIS AND CONCLUSION}

As was demonstrated throughout this paper, rooftop additions are now considered a viable form of urban development in Hamburg (such examples are shown in Fig. 3). They represent a significant potential in terms of number of housing units and can contribute to reducing the effects of gentrification downtown especially if rooftop projects are integrated with some form of subsidized housing program. This can help preserve a certain socio-economic diversity in downtown Hamburg and allow certain essential professions such as teachers, firefighters or police officers to reside in the city and near their workplace. The legal environment in the greater Hamburg area is now conducive to these kinds of projects as their economic feasibility is no longer in doubt. And though there are clear technical challenges to the execution of such projects, they are very manageable with proper planning and the recent advances made in the construction industry. The implementation of relatively new construction methods such as prefabricated structural wood systems offers speed of assembly, light weight and high building performance in line with European energy standards. With the use of appropriate materials and proper detailing, these prefabricated units can be very durable and make a long-term impact on housing demands within the city. Though potential heat gains need to be addressed, other unique advantages of these housing units include increased access to daylighting and views because of their unique location within the existing urban fabric.

The rooftop projects presented in this paper are within the specific context of a historical European city. It is clear that the specific nature of this context had an impact on the projects' visibility as it relates to the legal context, technology, resources and sustainable strategies. In a general context, such projects are challenging at a number of different levels and their occurrence has so far been limited to isolated cases. Though, as was demonstrated in the case of Hamburg, there is a real potential for this form of housing to contribute to a meaningful urban growth. Therefore, it is a model of development that could be applied in a variety of urban contexts around the world. A number of high-end residential rooftop projects have already been built in Europe and the US, but they are usually not part of a large scale concerted effort as is the case of Germany.

It is very conceivable for this type of housing project to be developed in other regions of the world including developing countries. With support from public institutions, a conducive legal environment can be developed as well as financial incentives. An important challenge remains though, which is the technical feasibility of such projects and the ability of existing buildings to receive an additional structure. Nevertheless, most urban buildings worldwide are either built with concrete, masonry, or steel therefore providing a potentially suitable base. Despite the lightweight nature of rooftop additions, important technical requirements will remain such as precisely aligning the bearing points of the new and existing buildings. The fact that these units are prefabricated and of high-quality would certainly contribute to improving housing standards especially in the case of affordable housing. The energy 

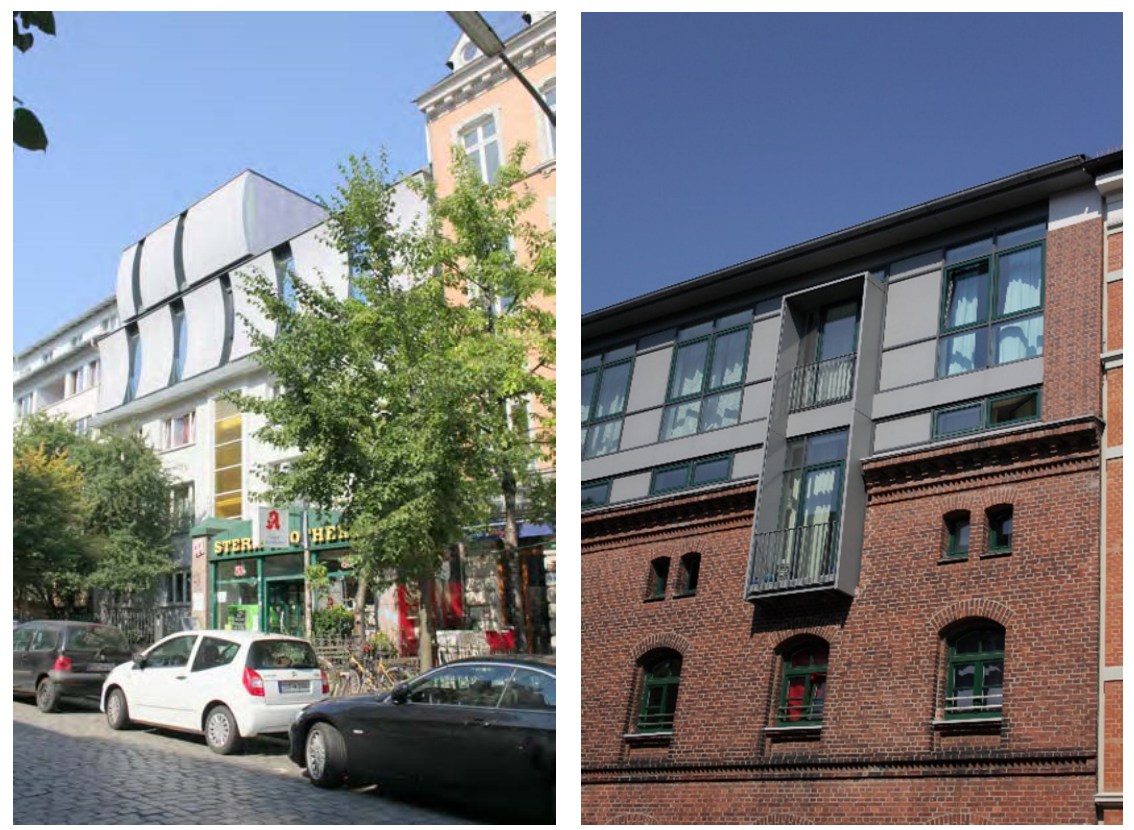

Figure 3: Examples of completed rooftop additions.

efficiency of these additions would have a tangible impact environmentally as most of the urban growth in the next 30 years is projected to occur in the global south (United Nations Sustainable Development Report 2020). But ultimately these types of urban dwellings would present a tool for cities to slow down sprawl and increase density in a sustainable manner. It would also have a measurable effect on the environmental consequences of urban growth around the globe. Just as vehicle manufacturers are pivoting to all electric vehicles around the world, the design community and construction industry needs to propose innovative urban design strategies. The ability to create quality affordable housing within large urban centers remains a challenge worldwide but is crucial to the socio-economic diversity of our cities so they can continue to be engines of development as well as a desirable place to live.

\section{REFERENCES}

[1] BBSR, Wo die bevölkerung in Europa wächst und wo sie schrumpft, 14 Jun. 2015. https://www.bbsr.bund.de/BBSR/DE/themen/_alt/Raumentwicklung/Raumentwicklu ngEuropa/Projekte/Bevoelkerungsentwicklung/Bevoelkerungsentwicklung.html.

[2] Behörde für Stadtentwicklung und Umwelt. Gutachten zu Potentialen von Dachgeschossaufstockung und-ausbau in Hamburg, 30 May 2018.

http://preview.poc.hamburg.de/hhcae-cm7/servlet/segment/transparenz.

[3] Beinhauer, P., Standard-Detail-Sammlung bauen im bestand: mit 199 detailkonstruktionen, Müller: Köln, 2009.

[4] Dahlgrün, B., Innerstädtische gebäudeaufstockungen in hamburg: konstruktive, rechtliche und gestalterische rahmenbedingungen, HafenCity Universität, 2016.

http://edoc.sub.uni-hamburg.de/hcu/frontdoor.php?source_opus=317. 
[5] Dalladas, O., GIS-Gestützte abschätzung des gebäudeaufstockungspotentials in hamburg. Master's thesis, HafenCity Universität Hamburg, 2017.

http://www.geomatik-hamburg.de/g2lab/hcu geb-aufstockung.html.

[6] Deutschland-Studie 2015: Wohnraumpotentiale durch aufstockungen, studie. darmstadt/Hannover: Technische universität darmstadt, ISP eduard pestel institut für systemforschung e. V., 29. Feb. 2016.

[7] Dorner, G., Tragwerksanalyse von aufstockungen in holzbauweise, masterarbeit, kunstuniversität, 2010. http://search.obvsg.at/primo_library/libweb/action/dlDisplay. do?vid=ACC\&docId=ACC_aleph008291955\&afterPDS=true.

[8] Glaeser, E.L., Triumph of the City: How our Greatest Invention Makes us Richer, Smarter, Greener, Healthier, and Happier, Penguin Books: New York, 2012.

[9] Eimsbütteler Nachrichten, Hamburg ist deutschlands stauhauptstadt, 30 Nov. 2016.

[10] Wietzorrek, U. \& Thomas J., Dachräume: Entwerfen, Konstruieren, Bewohnen. Erste Auflage, DETAIL Special, Edition DETAIL: München, 2018. 